Belén Gómara ${ }^{1}$

Carmen García-Ruiz ${ }^{2}$

María Luisa Marina ${ }^{1,2}$

${ }^{1}$ Centro de Tecnología de los

Alimentos y Servicios

Biosanitarios,

Universidad de Alcalá,

Alcalá de Henares,

Madrid, Spain

${ }^{2}$ Departamento de Química

Analítica, Facultad de Química,

Universidad de Alcalá,

Alcalá de Henares,

Madrid, Spain

\section{Enantioselective separation of the sunscreen agent 3-(4-methylbenzylidene)-camphor by electrokinetic chromatography: Quantitative analysis in cosmetic formulations}

\begin{abstract}
3-(4-Methylbenzylidene)-camphor (MBC) is a chiral sunscreen agent used in cosmetic products. In this work, the enantioseparation of $\mathrm{MBC}$ has been performed by EKC and applied to the analysis of the MBC enantiomers in cosmetic creams. Different experimental conditions (type and concentration of the chiral selector, temperature, and sample solvent) have been optimized. Due to the neutral nature of this compound, anionic $C D$ derivatives were investigated as chiral selectors. Carboxymethylated- $\beta-C D$ $(C M-\beta-C D)$ showed the highest chiral separation power, observing that a $15 \mathrm{~mm}$ concentration of this $\mathrm{CD}$ at a working temperature of $15^{\circ} \mathrm{C}$ enabled to obtain the highest enantioresolution. However, under these conditions, tailing of peaks obtained for the enantiomers was observed. The addition of increasing concentrations of the neutral $\alpha-C D$ to $C M-\beta-C D$ at a $15 \mathrm{~mm}$ concentration in a $100 \mathrm{~mm}$ borate buffer at $\mathrm{pH} 9.0$ improved the enantiomeric separation and decreased peak tailing. The use of DMF for the total dissolution of the cosmetic creams, and methanol:water (1:1 v/v) for appropriate dilution enabled to observe good shape and size for the peaks of the MBC enantiomers. After optimizing a method for the preconditioning of the capillary, the analytical characteristics of the chiral separation method for the analysis of MBC were investigated. Linearity, LODs and LOQs, precision (instrumental repeatability, method repeatability, intermediate precision), accuracy, and selectivity were evaluated. The method was applied to analyze MBC enantiomers contained in two commercial cosmetic creams containing racemic $\mathrm{MBC}$ and to study the skin absorption of this compound with time.
\end{abstract}

Keywords: Cosmetic creams; Cyclodextrins; Electrokinetic chromatography; Enantioselective analysis; 3-(4-Methylbenzylidene)-camphor

\section{Introduction}

3-(4-Methylbenzylidene)-camphor (MBC) is a chiral compound added as a racemic mixture of its two enantiomers (see Fig. 1) in commercial sun protection products, such as cosmetic creams. This compound acts as UV filter in these products. However, this sunscreen chemical may cause health problems, since it can interfere with the

Correspondence: Professor María Luisa Marina, Departamento de Química Analítica, Facultad de Química, Universidad de Alcalá, Ctra. Madrid-Barcelona Km. 33.600, E-28871 Alcalá de Henares, Madrid, Spain

E-mail: mluisa.marina@uah.es

Fax: +34-91-885-4971

Abbreviations: ANOVA, analysis of variance; CE- $\beta$-CD, carboxyethylated- $\beta-C D ; C E-\gamma-C D$, carboxyethylated- $\gamma-C D ; C M-\alpha-C D$, carboxymethylated- $\alpha-C D$; CM- $\beta-C D$, carboxymethylated- $\beta-C D$; CM- $\gamma-\mathbf{C D}$, carboxymethylated- $\gamma-C D ;$ MBC, 3-(4-methylbenzylidene)-camphor; Succ- $\beta-C D$, succinylated- $\beta-C D$; Succ- $\gamma-C D$, succinylated- $\gamma-C D$
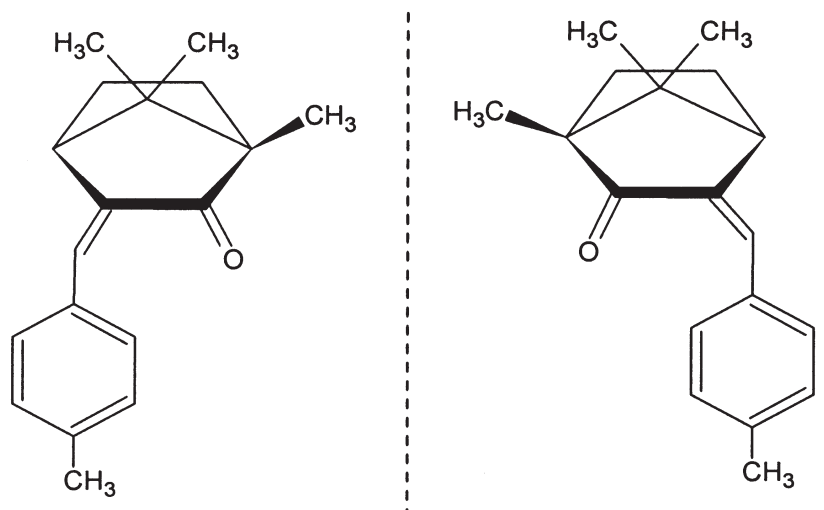

Figure 1. Structure of $M B C$ enantiomers.

normal functions of human hormone estrogen [1] or produce some allergic reactions [2]. This is why the percentage of MBC, as well as of other cosmetic chemicals, in cosmetic formulations is regulated in the European Union. In 
the Spanish legislation, the MBC concentration in cosmetic products must be lower than $4 \%$ [3]. As a consequence, analytical methodologies to control the levels of this compound in cosmetic products are needed. However, in the literature, there are only a few papers dealing with the analysis of sunscreen agents in cosmetic formulations. UVfilters have been analyzed in cosmetic products using CE [4-7], HPLC [6-14], or UV-Vis spectrophotometry [15, 16]. These works were focused on the identification and/or quantitation of the total content of the studied UV-filters in mixtures from 2 to 24 compounds. In the case of $C E$, until now only the microemulsion EKC (MEEKC) mode $[4,5]$ has been applied to the separation [4] and the quantitative determination [5] in sunscreen lotions of nine UV-filters, including MBC among them. Nevertheless, as far as we know there is no reference in the literature on the development and application of an analytical method for the enantioselective separation of the chiral UV filter MBC.

Enantioselective analysis of chiral compounds is important because nature is able to discriminate among the enantiomers of a chiral compound, that is, each enantiomer of a chiral compound may have a different biological activity. As an example, the case of an MBC structurally related compound, camphorquinone, can be cited. In fact, degradation of camphorquinone by yeast was recently reported to be enantioselective [17]. Then, the development of chiral methods of analysis for MBC has a high interest in order to study the bioactivity of this sunscreen agent in nature. CE is a separation technique with a high potential in the field of chiral analysis which has been reported in hundreds of scientific papers, a wide number of reviews, several issues of international journals dedicated to enantioseparations [18-22], and even a book [23]. For this reason, the CE working mode of EKC was used in this work to carry out the chiral separation of MBC using CDs as chiral selectors. Our goal was to develop a chiral separation method by EKC to achieve the enantiomeric separation of $\mathrm{MBC}$ and to apply it to the quantitation of this chiral compound in commercial sun creams and to study the MBC skin absorption with time.

\section{Materials and methods}

\subsection{Reagents and samples}

All reagents employed for the preparation of the separation buffers were of analytical grade. DMF was supplied from Sigma (Madrid, Spain) and methanol was from LabScan (Dublin, Ireland). Boric acid and sodium hydroxide were supplied from Panreac (Barcelona, Spain). MBC standard was purchased from ABCR GmbH \& Co. (Karlsruhe, Germany). Carboxymethylated- $\beta-C D$ (CM- $\beta-C D$,
$D S \sim 3$ ) and $\alpha-C D$ were purchased from Fluka (Buchs, Switzerland). Carboxymethylated- $\gamma-\mathrm{CD} \quad(\mathrm{CM}-\gamma-\mathrm{CD}$, $\mathrm{DS} \sim 3)$, carboxymethylated- $\alpha-\mathrm{CD}(\mathrm{CM}-\alpha-\mathrm{CD}, \mathrm{DS} \sim 3)$, carboxyethylated- $\beta-C D$ (CE- $\beta-C D, D S \sim 3)$, carboxyethylated- $\gamma-C D(C E-\gamma-C D, D S \sim 4)$, succinylated- $\beta-C D$ (Succ- $\beta-C D$, DS $\sim 3$ ), and succinylated- $\gamma$-CD (Succ- $\gamma$ CD, DS 3) were from Cyclolab (Budapest, Hungary). Water used to prepare solutions was purified through a Milli-Q system from Millipore (Bedford, MA, USA). Solutions were filtered prior use through $0.45 \mu \mathrm{m}$ pore size disposable nylon filters from Sugelabor (Madrid, Spain). The cosmetic creams analyzed were commercially available and acquired from a chemist in Amsterdam, The Netherlands (cosmetic cream A, composed of MBC (3 g per $100 \mathrm{~g}$ sample), 4-tert-butyl-4'-methoxy-dibenzoylmethane, sodium 2-phenyl-benzidimazol-5-sulfonate, and bronopol) and from a market in Madrid, Spain (cosmetic cream B, composed of MBC, isopropyl stearate, caprylic/capric/triglyceride, octyl metoxycinnamate, paraffinum liquidum, cetyl dimethicone copolyol, $\mathrm{C}_{12}-\mathrm{C}_{15}$ alkyl benzoate, phenylbenzidimazole sulfonic acid, butyl metoxidibenzoyl methane, titanium dioxide, polygliceryl4-isostearate, sodium chloride, phenoxyethanol, hydrogenated castor oil, methylparaben, ethylparaben, propylparaben, butylparaben, tocopheryl acetate, panthenol, and retinyl palmitate).

\subsection{Apparatus}

All experiments were performed on an $\mathrm{HP}^{3 \mathrm{D}} \mathrm{CE}$ system (Hewlett-Packard, Waldbronn, Germany) equipped with an on-column diode array detector (DAD). Instrument control and data acquisition were performed with the $\mathrm{HP}^{3 \mathrm{D}} \mathrm{CE}$ ChemStation software (Hewlett Packard). Separations were performed on untreated fused-silica capillaries of $50 \mu \mathrm{m}$ ID and $375 \mu \mathrm{m}$ OD, purchased from Composite Metal Services (Worcester, England). Capillaries had a total length of $58.5 \mathrm{~cm}$ and an effective length of $50 \mathrm{~cm}$. Capillary temperature was $15^{\circ} \mathrm{C}$ and UV detection was performed at $300 \mathrm{~nm}$ with a bandwidth (wavelength range where compounds are detected) of $50 \mathrm{~nm}$ $(300 \pm 25 \mathrm{~nm})$ and a response time of $0.1 \mathrm{~s}$. A PHM-93 $\mathrm{pH}$-meter from Radiometer (Copenhagen, Denmark) was used to adjust the $\mathrm{pH}$ of the separation buffers.

\subsection{Procedure}

Before first use, the capillary was flushed (4 bar) with $1 \mathrm{M} \mathrm{NaOH}$ for $30 \mathrm{~min}$, followed by $20 \mathrm{~min}$ with water, and 20 min with the separation buffer. Between injections of samples, the capillary was conditioned (4 bar) with methanol:water $(1: 1, v / v)$ for $2 \mathrm{~min}$ followed by $0.1 \mathrm{M}$ 
$\mathrm{NaOH}$, Milli-Q water, and the separation buffer for 2 min each. Injections were made by pressure (50 mbar for $3 \mathrm{~s}$ ), and the applied voltage was $20 \mathrm{kV}$.

Separation buffer solutions were prepared by dissolving the appropriate amount of boric acid $(100 \mathrm{~mm})$ with the appropriate amount of each CD in Milli-Q water. The $\mathrm{pH}$ value was adjusted at 9.0 by addition of $\mathrm{NaOH}(1 \mathrm{M})$. These solutions were filtered through $0.45 \mu \mathrm{m}$ pore size nylon filter membrane before use in the CE system.

Stock solutions were prepared by dissolving the appropriate amount of MBC in DMF to achieve a final concentration of $10000 \mathrm{mg} / \mathrm{L}$. This solution was diluted in methanol:water $(1: 1 \mathrm{v} / \mathrm{v})$ to get diluted solutions with different concentrations of MBC.

Sample solutions of the two commercial cosmetic creams analyzed were prepared by weighing about $0.5 \mathrm{~g}$ cream and dissolving it in $15 \mathrm{~mL}$ DMF. These sample solutions were diluted ten times in methanol:water $(1: 1 \mathrm{v} / \mathrm{v})$ to get the injection solutions.

Sample solutions for the skin absorption study were prepared by applying about $0.5 \mathrm{~g}$ of the cosmetic cream A to an area of $20 \mathrm{~cm} \times 6 \mathrm{~cm}$ of skin $\left(120 \mathrm{~cm}^{2}\right)$, waiting for 0,1 , 3,5 , and $10 \mathrm{~min}$, taking the residual cream with a spatula, and dissolving it in $15 \mathrm{~mL}$ DMF. These sample solutions were diluted ten times in methanol:water $(1: 1 \mathrm{v} / \mathrm{v})$ before injecting in the CE system.

\subsection{Data treatment}

Resolution of the MBC enantiomers was obtained from the ChemStation software using the equation $R_{\mathrm{s}}=1.18 \frac{t_{2}-t_{1}}{w_{1 / 2,1}+w_{1 / 2,2}}$, where $t_{1}$ and $t_{2}$ are the migration times of the first- and second-migrating enantiomers, respectively, and $w_{1 / 2,1}, w_{1 / 2,2}$ are their peak widths at halfheight.

Corrected peak areas $\left(A_{\mathrm{c}}\right)$ and corrected migration times $\left(t_{\mathrm{c}}\right)$ have been used to compensate fluctuations in electrophoretic conditions and to obtain a good reproducibility of data [24]. They have been calculated by dividing the peak area $(A)$ by the corresponding migration time $(t)$ and the migration times $(t)$ by the migration time of the EOF $\left(t_{\mathrm{EOF}}\right)$, which was measured as the migration time corresponding to the solvent peak (methanol peak), that is, $A_{\mathrm{c}}=A / t$ and $t_{\mathrm{c}}=t / t_{\mathrm{EOF}}$

Concentration LODs $\left(3 s_{\mathrm{a}} / b\right)$ and LOQs $\left(10 s_{\mathrm{a}} / b\right)$ were determined from the standard error of the intercept $\left(s_{\mathrm{a}}\right)$ and the slope $(b)$ of the calibration curve obtained by analysis of variance (ANOVA) [25].
Experimental data analysis and parameters were calculated using Excel Microsoft $\mathrm{XP}^{\circledR}$ and Origin 7.0. Comparison of the slopes of regression lines was made using the $F$ - and $t$-tests [25]. Graphs with different electropherograms were composed in Origin 7.0.

\section{Results and discussion}

\subsection{Development of an enantioselective analytical method for MBC by EKC}

The first step, and the most important one, was the selection of a chiral selector for MBC. Since CDs have shown to be chiral selectors in EKC with a high discrimination power, and the analyte under study was neutral, different anionic CDs (CM- $\beta-C D, C M-\gamma-C D$, CE- $\beta$ CD, CE- $\gamma-C D$, Succ- $\beta-C D$, and Succ- $\gamma-C D$ ) at a $10 \mathrm{~mm}$ concentration were investigated. These experiments were performed using a $100 \mathrm{~mm}$ borate buffer at $\mathrm{pH} 9.0$ and a working temperature of $25^{\circ} \mathrm{C}$. Borate buffer was chosen since a basic $\mathrm{pH}$ enabled to have an EOF enough to move the anionic CDs to the detector. Among these CDs, only CM- $\beta-C D$ and Succ- $\beta-C D$ enabled the discrimination of the two enantiomers of MBC, CM- $\beta-C D$ being the chiral selector giving rise to the highest enantiomeric resolution $\left(R_{\mathrm{s}} \sim 1.4\right)$. As a consequence, CM- $\beta$ $C D$ at a $10 \mathrm{~mm}$ concentration was selected in order to study the effect of the temperature since its influence on the enantiomeric resolution may be considerable as it has been demonstrated for other analytes [26, 27]. The variation of the enantiomeric resolution and the migration time for the two MBC enantiomers as a function of the temperature of the capillary was determined (results not shown). It could be observed that, as in the case of other chiral analytes enantiomerically separated by EKC with CDs as chiral selectors [23], the enantiomeric resolution increased when decreasing the temperature, although enantiomer migration times increased when decreasing the temperature due to the increment in solution viscosity. As a result, a temperature of $15^{\circ} \mathrm{C}$ was chosen in order to study the effect of $C M-\beta-C D$ concentration (in the range from 5 to $20 \mathrm{~mm}$ ) on the enantiomeric resolution for MBC. The results obtained enabled to observe that $15 \mathrm{~mm}$ CM$\beta-C D$ provided the highest enantiomeric discrimination. However, under these conditions an important distortion of the peak corresponding to the first-migrating enantiomer was observed. In order to improve peak shape and resolution, $1 \mathrm{~m}$ urea was added to $15 \mathrm{~mm} C M-\beta-C D$ in $100 \mathrm{~mm}$ borate buffer at $\mathrm{pH} 9.0$. In fact, urea has previously been shown to improve peak shape for other neutral aromatic compounds probably because it enables the better solubilization of them and CDs in the aqueous buffer [28]. However, in the case of MBC enantiomers the 
addition of urea did not improve the enantiomeric resolution. In addition, a carboxymethylated CD derivative with a smaller inner core, $\mathrm{CM}-\alpha-\mathrm{CD}$, was used as chiral selector at two usual and different concentrations (30 and $60 \mathrm{~mm}$ ) but the resolution of MBC enantiomers was not observed (results not shown). Since $\alpha-C D$ has already shown good enantioresolution power for a bicyclic compound as it is camphorquinone [17], we studied the effect of this $C D$ on the peak shape and enantioresolution of $\mathrm{MBC}$, which is a compound with a bicyclic ring in addition to an aromatic ring (see Fig. 1). Then, increasing concentrations of $\alpha-\operatorname{CD}(30,60,90$, and $120 \mathrm{~mm})$ were added to $15 \mathrm{~mm} C M-\beta-C D$ in $100 \mathrm{~mm}$ borate buffer at $\mathrm{pH} 9.0$ in order to decrease the peak tailing observed. It could be observed (results not shown) that the enantiomeric resolution of MBC increased when increasing $\alpha-C D$ concentration. In addition, the use of $\alpha-C D$ in the separation medium also contributed to obtain different separation selectivities with respect to the peaks corresponding to the other components of the cosmetic creams studied when these samples were injected in the electrophoretic system. Figure 2 shows the electropherograms obtained for the two sunscreen creams studied ( $A$ and $B$ ) when using $15 \mathrm{~mm} C M-\beta-C D$ in 100 mм borate buffer at $\mathrm{pH} 9.0$ in absence and in presence of $120 \mathrm{~mm} \alpha$-CD. It is interesting to observe that peaks corresponding to other components of the creams migrated after MBC enantiomers peak in absence of $\alpha$-CD whereas a higher separation of the sample components, which appeared at

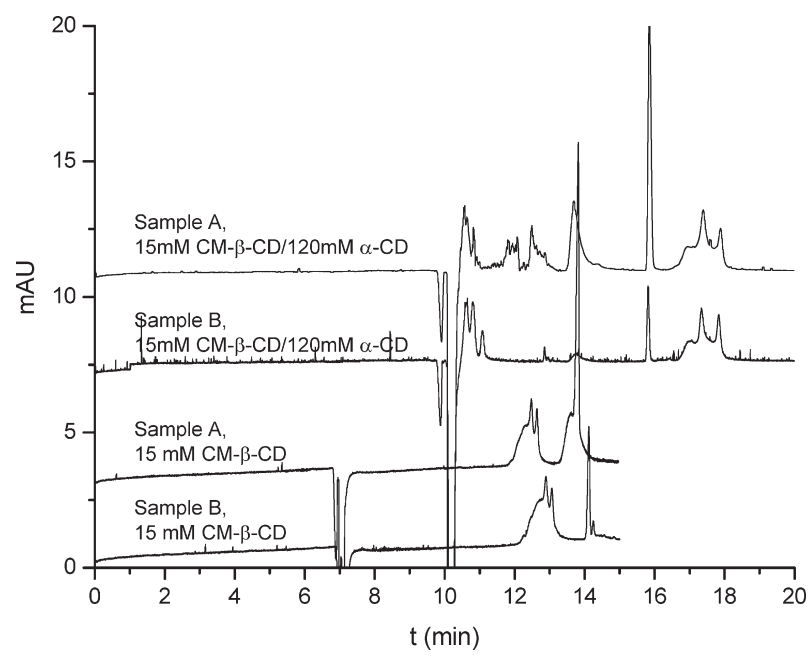

Figure 2. Electropherograms corresponding to the commercial cosmetic formulations $A$ and $B(100 \mathrm{mg} / \mathrm{L}$, about $0.5 \mathrm{~g}$ dissolved in $15 \mathrm{~mL}$ DMF and diluted 1:10 with DMF) in $100 \mathrm{~mm}$ borate buffer at $\mathrm{pH} 9.0$ with $15 \mathrm{~mm}$ CM- $\beta$-CD without and with $120 \mathrm{~mm} \alpha-C D$. Untreated fused-silica capillary, $58.5 \mathrm{~cm}(50 \mathrm{~cm}$ to the detector window) $\times$ $50 \mu \mathrm{m}$ ID; separation temperature, $15^{\circ} \mathrm{C}$; applied voltage, $20 \mathrm{kV}$; injection, $50 \mathrm{mbar} \times 3 \mathrm{~s}$. UV-detection at $300 \pm 25 \mathrm{~nm}$. shorter migration times than $\mathrm{MBC}$ enantiomers, was observed in presence of $120 \mathrm{~mm} \alpha-C D$. Nevertheless, peak tailing did not disappear under these conditions. This undesirable effect was eliminated by changing the solvent of the standard and sample solutions. Figure 3 shows the effect of different solvents on the shape and size of the MBC peaks using the dual CD system based on $15 \mathrm{~mm} C M-\beta-C D / 120 \mathrm{~mm} \alpha-C D$, which provided the highest enantiomeric discrimination. It can be observed that a mixture of methanol:water $(1: 1 \mathrm{v} / \mathrm{v})$ as solvent enabled the best peak shape and size. Therefore, we chose this mixture to prepare the adequate dilutions of the standard solutions and samples initially dissolved in DMF because it enabled to dissolve totally the cosmetic creams studied in this work.

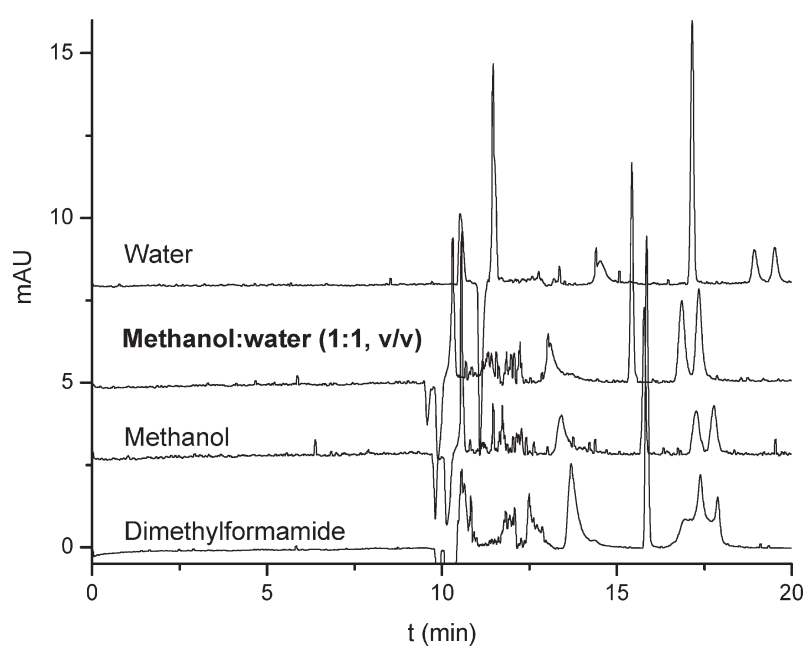

Figure 3. Electropherograms corresponding to the commercial cosmetic product A (previously dissolved in DMF) diluted in different solvents. One hundred millimolar borate buffer at $\mathrm{pH} 9.0$ with $15 \mathrm{~mm}$ CM- $\beta-\mathrm{CD}$ and $120 \mathrm{~mm}$ $\alpha$-CD. Other experimental conditions as in Fig. 2.

\subsection{Quantitative analysis of MBC enantiomers by EKC}

Before studying the analytical characteristics of the chiral method developed for the analysis of MBC enantiomers, three different methods for preconditioning the capillary were tested. Table 1 shows the steps followed for each preconditioning method and the RSD values obtained for corrected peak area, corrected migration time, and enantiomeric resolution for five duplicated injections of sample A (each duplicate was injected with the same buffer solution which was replaced for each one of the five duplicated injections). It can be observed that the preconditioning method III enabled to obtain the lowest RSD values for corrected migration time $(0.19 \%)$ and enantioresolution $(2.8 \%)$. As a consequence, this method was 
Table 1. Methods tested for preconditioning the capillary for the analysis of MBC

\begin{tabular}{|c|c|c|c|c|c|c|}
\hline \multirow{3}{*}{$\begin{array}{l}\text { Preconditioning } \\
\text { methods }\end{array}$} & \multirow[t]{3}{*}{ Steps } & \multicolumn{5}{|c|}{ RSD in $\%(n=5)$} \\
\hline & & \multicolumn{2}{|c|}{$\begin{array}{l}\text { First-migrating } \\
\text { enantiomer }\end{array}$} & \multicolumn{2}{|c|}{$\begin{array}{l}\text { Second- } \\
\text { migrating } \\
\text { enantiomer }\end{array}$} & \multirow[t]{2}{*}{$R_{\mathrm{s}}$} \\
\hline & & $A_{\mathrm{c}}$ & $t_{\mathrm{c}}$ & $A_{\mathrm{c}}$ & $t_{\mathrm{c}}$ & \\
\hline 1 & $\begin{array}{l}0.1 \mathrm{~m} \mathrm{NaOH} \text { ( } 4 \text { bar) for } 2 \text { min } \\
\text { Milli-Q water ( } 4 \text { bar) for } 2 \text { min } \\
\text { separation buffer ( } 4 \text { bar) for } 2 \text { min }\end{array}$ & 4.9 & 0.24 & 4.6 & 0.27 & 5.3 \\
\hline II & $\begin{array}{l}\text { DMF ( } 4 \text { bar) for } 2 \text { min } \\
0.1 \mathrm{M} \mathrm{NaOH}(4 \text { bar) for } 2 \text { min } \\
\text { Milli-Q water ( } 4 \text { bar) for } 2 \text { min } \\
\text { separation buffer ( } 4 \text { bar) for } 2 \text { min }\end{array}$ & $8.0^{\mathrm{a})}$ & 1.82 & $8.4^{\mathrm{a})}$ & 2.74 & $6.6^{a)}$ \\
\hline III & $\begin{array}{l}\text { Methanol:water (1:1, v/v) (4 bar) } \\
\text { for } 2 \text { min } \\
0.1 \mathrm{M} \mathrm{NaOH} \text { (4 bar) for } 2 \text { min } \\
\text { Milli-Q water ( } 4 \text { bar) for } 2 \text { min } \\
\text { separation buffer ( } 4 \text { bar) for } 2 \text { min }\end{array}$ & 3.8 & 0.18 & 5.2 & 0.19 & 2.8 \\
\hline
\end{tabular}

$A_{\mathrm{c}}$ : corrected peak area; $t_{\mathrm{c}}$ : corrected migration time a) $n=4$

selected for preconditioning the capillary walls before injections. In addition, preconditioning method using DMF as first step (method II) produced broad peaks and sensitivity losses, probably due to the effect of DMF on the $\mathrm{MBC} / \mathrm{CD}$ interactions.

The analytical characteristics of the enantioselective method developed were studied in order to evaluate the quality, reliability, and consistency of its results. Linearity, LODs and LOQs, precision, accuracy, and selectivity were evaluated.

The linearity was studied by plotting the corrected peak area $\left(A_{c}\right)$ as a function of the analyte concentration in $\mathrm{mg} / \mathrm{L}$. Six standard solutions containing racemic MBC from 10 to $1000 \mathrm{mg} / \mathrm{L}$ (each one injected in triplicate) were employed. The chiral method enabled to study separately each enantiomer, whose concentrations ranged from 5 to $500 \mathrm{mg} / \mathrm{L}$. ANOVA analysis enabled to confirm that experimental data fit properly to linear models for both enantiomers ( $p$-values of 0.071 and 0.076 for the first- and second-migrating enantiomers, respectively $(\alpha=0.05))$. The linear working concentration range for the racemate and MBC enantiomers as well as the linear equations for each enantiomer are shown in Table 2. This table also shows the concentration LODs and LOQs for MBC enantiomers calculated from the calibration line parameters. An LOD of $10 \mathrm{mg} / \mathrm{L}$ and LOQ of $27 \mathrm{mg} / \mathrm{L}$ for the first-migrating enantiomer, and LOD of $12 \mathrm{mg} / \mathrm{L}$ and $\mathrm{LOQ}$ of $31 \mathrm{mg} / \mathrm{L}$ for the second-migrating enantiomer were obtained. These concentration values were adequate to quantitate $\mathrm{MBC}$ in cosmetic formulations.

Precision was evaluated considering the instrumental and method repeatability as well as the intermediate precision. Instrumental repeatability was determined from six repeated injections of two standard solutions at two different concentration levels ( 50 and $100 \mathrm{mg} / \mathrm{L}$ of MBC). In both cases, RSD values lower than $4.3 \%$ for corrected peak area and lower than $0.6 \%$ for corrected migration time were obtained (see Table 2). The method repeatability was assessed with six replicate standard solutions of 50 and $100 \mathrm{mg} / \mathrm{L}$ of MBC as well as six replicates of a sample solution (cosmetic cream A) injected in triplicate on the same day. RSD values for both standard solutions were lower than $8.7 \%$ for corrected peak area and lower than $0.8 \%$ for corrected migration time. RSD values for the sample solution were lower than $7.1 \%$ for corrected peak area and lower than $1.3 \%$ for corrected migration time (see Table 2). The intermediate precision of the method was calculated for three freshly prepared standard solutions of MBC containing 50,100 , and $500 \mathrm{mg} / \mathrm{L}$ and injected in triplicate for five different days and with two different capillaries. In this case, RSD values were lower than $2.4 \%$ for corrected migration time and lower than $11.0 \%$ for corrected peak area.

Accuracy was estimated as the recovery obtained for MBC enantiomers when spiking the cosmetic cream A with known concentrations of $\operatorname{MBC}(25,62.5$, and 
Table 2. Analytical characteristics of the method developed for the analysis of MBC enantiomers

\begin{tabular}{|c|c|c|c|}
\hline \multicolumn{2}{|c|}{ Linear working concentration range } & \multicolumn{2}{|c|}{$\begin{array}{l}\text { Racemate: } 10-1000 \mathrm{mg} / \mathrm{L} \\
\text { Enantiomers: } 5-500 \mathrm{mg} / \mathrm{L}\end{array}$} \\
\hline \multicolumn{2}{|c|}{ Linear equation first-migrating enantiomer } & \multicolumn{2}{|c|}{$\begin{array}{l}A_{\mathrm{c}}=0.0382 c-0.1026 \\
\left(s_{\mathrm{b}}=0.0004 ; s_{\mathrm{a}}=0.0947 ; r=0.9998 ; n=6\right)\end{array}$} \\
\hline \multicolumn{2}{|c|}{ Linear equation second-migrating enantiomer } & \multicolumn{2}{|c|}{$\begin{array}{l}A_{\mathrm{c}}=0.0404 c-0.1383 \\
\left(s_{\mathrm{b}}=0.0005 ; s_{\mathrm{a}}=0.1119 ; r=0.9997 ; n=6\right)\end{array}$} \\
\hline \multirow[t]{2}{*}{ Detection limits } & $\begin{array}{l}\text { First-migrating } \\
\text { enantiomer }\end{array}$ & \multicolumn{2}{|l|}{$10 \mathrm{mg} / \mathrm{L}$} \\
\hline & $\begin{array}{l}\text { Second-migrating } \\
\text { enantiomer }\end{array}$ & \multicolumn{2}{|l|}{$12 \mathrm{mg} / \mathrm{L}$} \\
\hline \multirow[t]{2}{*}{ Quantitation limits } & $\begin{array}{l}\text { First-migrating } \\
\text { enantiomer }\end{array}$ & \multicolumn{2}{|l|}{27 mg/L } \\
\hline & $\begin{array}{l}\text { Second-migrating } \\
\text { enantiomer }\end{array}$ & \multicolumn{2}{|l|}{$31 \mathrm{mg} / \mathrm{L}$} \\
\hline \multicolumn{2}{|l|}{ Precision } & $\begin{array}{l}\text { First-migrating } \\
\text { enantiomer }\end{array}$ & $\begin{array}{l}\text { Second-migrating } \\
\text { enantiomer }\end{array}$ \\
\hline \multicolumn{4}{|c|}{ Instrumental repeatability $(n=6)$} \\
\hline $50 \mathrm{mg} / \mathrm{L} \mathrm{MBC}$ & $\begin{array}{l}A_{c}, \text { RSD in } \% \\
t_{c}, \text { RSD in } \%\end{array}$ & $\begin{array}{l}4.3 \\
0.5\end{array}$ & $\begin{array}{l}3.4 \\
0.6\end{array}$ \\
\hline 100 mg/L MBC & $\begin{array}{l}A_{\mathrm{c}}, \mathrm{RSD} \text { in } \% \\
t_{\mathrm{c}}, \mathrm{RSD} \text { in } \%\end{array}$ & $\begin{array}{l}3.0 \\
0.3\end{array}$ & $\begin{array}{l}3.2 \\
0.3\end{array}$ \\
\hline \multicolumn{4}{|c|}{ Method repeatability $(n=6)$} \\
\hline 50 mg/L MBC & $\begin{array}{l}A_{c}, \text { RSD in } \% \\
t_{c}, \text { RSD in } \%\end{array}$ & $\begin{array}{l}6.5 \\
0.5\end{array}$ & $\begin{array}{l}8.7 \\
0.6\end{array}$ \\
\hline 100 mg/L MBC & $\begin{array}{l}A_{\mathrm{c}}, \mathrm{RSD} \text { in } \% \\
t_{\mathrm{c}}, \mathrm{RSD} \text { in } \%\end{array}$ & $\begin{array}{l}4.3 \\
0.7\end{array}$ & $\begin{array}{l}6.0 \\
0.8\end{array}$ \\
\hline $\begin{array}{l}\text { Cosmetic cream A } \\
(\sim 100 \mathrm{mg} / \mathrm{L} \mathrm{MBC})\end{array}$ & $\begin{array}{l}A_{c}, \text { RSD in } \% \\
t_{c}, \text { RSD in } \%\end{array}$ & $\begin{array}{l}6.9 \\
1.2\end{array}$ & $\begin{array}{l}7.1 \\
1.3\end{array}$ \\
\hline \multicolumn{4}{|c|}{ Intermediate precision $(n=15)$} \\
\hline $50 \mathrm{mg} / \mathrm{L} \mathrm{MBC}$ & $\begin{array}{l}A_{\mathrm{c}}, \mathrm{RSD} \text { in } \% \\
t_{\mathrm{c}}, \mathrm{RSD} \text { in } \%\end{array}$ & $\begin{array}{l}6.4 \\
1.4\end{array}$ & $\begin{array}{l}8.6 \\
1.5\end{array}$ \\
\hline 100 mg/L MBC & $\begin{array}{l}A_{\mathrm{c}}, \mathrm{RSD} \text { in } \% \\
t_{\mathrm{c}}, \mathrm{RSD} \text { in } \%\end{array}$ & $\begin{array}{l}8.5 \\
2.2\end{array}$ & $\begin{array}{l}8.9 \\
2.4\end{array}$ \\
\hline $500 \mathrm{mg} / \mathrm{L} \mathrm{MBC}$ & $\begin{array}{l}A_{\mathrm{c}}, \mathrm{RSD} \text { in } \% \\
t_{\mathrm{c}}, \mathrm{RSD} \text { in } \%\end{array}$ & $\begin{array}{r}10.0 \\
2.1\end{array}$ & $\begin{array}{r}11.0 \\
2.3\end{array}$ \\
\hline \multicolumn{2}{|l|}{ Accuracy } & $\begin{array}{l}\text { First-migrating } \\
\text { enantiomer }\end{array}$ & $\begin{array}{l}\text { Second-migrating } \\
\text { enantiomer }\end{array}$ \\
\hline \multicolumn{4}{|l|}{ Recovery (\%) } \\
\hline \multicolumn{2}{|c|}{$\begin{array}{l}25 \mathrm{mg} / \mathrm{L} \text { of the } \mathrm{MBC} \text { enantiomer added } \\
\text { to the cream } \mathrm{A}\end{array}$} & $104 \pm 1$ & $103 \pm 2$ \\
\hline \multicolumn{2}{|c|}{$\begin{array}{l}62.5 \mathrm{mg} / \mathrm{L} \text { of the } \mathrm{MBC} \text { enantiomer added } \\
\text { to the cream } \mathrm{A}\end{array}$} & $90 \pm 11$ & $89 \pm 11$ \\
\hline \multicolumn{2}{|c|}{$\begin{array}{l}100 \mathrm{mg} / \mathrm{L} \text { of the } \mathrm{MBC} \text { enantiomer added } \\
\text { to the cream } \mathrm{A}\end{array}$} & $104 \pm 6$ & $102 \pm 6$ \\
\hline \multicolumn{2}{|l|}{ Mean recovery (\%) } & $99 \pm 9$ & $98 \pm 9$ \\
\hline
\end{tabular}

$c$, concentration; $s_{\mathrm{a}}$, standard error of the intercept; $s_{\mathrm{b}}$, standard error of the slope; $r$, correlation coefficient

(c) 2005 WILEY-VCH Verlag GmbH \& Co. KGaA, Weinheim 
$100 \mathrm{mg} / \mathrm{L}$ of each enantiomer) and comparing these concentration values with those determined by the EKC method using the external standard method for calibration. Each standard addition level was performed in triplicate. Table 2 shows that recovery values ranged from $90 \pm 11$ to $104 \pm 6 \%$ for the first-migrating enantiomer and from $89 \pm 11$ to $103 \pm 2 \%$ for the second-migrating enantiomer with mean recoveries of $99 \pm 9$ and $98 \pm 9$, respectively.

Appropriate separation selectivity was observed for the chiral method developed since the peaks observed for other components of the creams did not interfere with the MBC peaks. Thus, all the peaks corresponding to the other components of cosmetic creams $A$ and $B$ migrated before the peaks corresponding to $\mathrm{MBC}$ enantiomers not producing any interference with the analyte (see Figs. 2, 3). In addition, the existence of possible matrix interferences was investigated by comparing the calibration slopes obtained by the external standard and the standard addition calibration methods. The results obtained by $F$ - and $t$-tests $(p<0.05)[25]$ showed that there were not statistically significant differences between the slopes obtained by the external standard and the standard addition calibration methods for both enantiomers. This fact showed that the external standard calibration method can be used to achieve the quantitation of MBC enantiomers in cosmetic cream samples.

\subsection{Applications}

The chiral method developed for the analysis of MBC enantiomers was applied for two different purposes: (i) to quantitate the MBC enantiomers in two commercial cosmetic creams containing this compound as racemate in their formulation and (ii) to study the skin absorption of one cosmetic cream (commercial cosmetic A) with time.

The amount of MBC enantiomers determined in the two commercial formulations analyzed in this work is shown in Table 3. The quantitation of MBC enantiomers enabled to determine the total MBC content in the cosmetic creams analyzed. In the case of the commercial cream A, the amount determined by the developed method was $13.1 \pm 0.6 \mathrm{mg}$ of $\mathrm{MBC}$ in $0.5 \mathrm{~g}$ of sample, being the amount indicated in the label of the product $15 \mathrm{mg}$ of $\mathrm{MBC}$ in $0.5 \mathrm{~g}$ of sample. For the commercial cream B, for which the label of the product did not specify the amount of MBC added, an amount of $8.4 \pm 0.5 \mathrm{mg}$ of $\mathrm{MBC}$ in $0.5 \mathrm{~g}$ of sample was determined.

Finally, the method developed was applied to perform a preliminary study of the skin absorption of the cosmetic cream A with time. Figure 4 shows the variation in the areas of the peaks corresponding to the MBC enantiomers and other components of the cosmetic cream $A$ when this cream was applied to $120 \mathrm{~cm}^{2}$ of skin for 0,5 , and $10 \mathrm{~min}$. From this figure, it can be observed that under these experimental conditions the absorption of both enantiomers by the skin was similar.

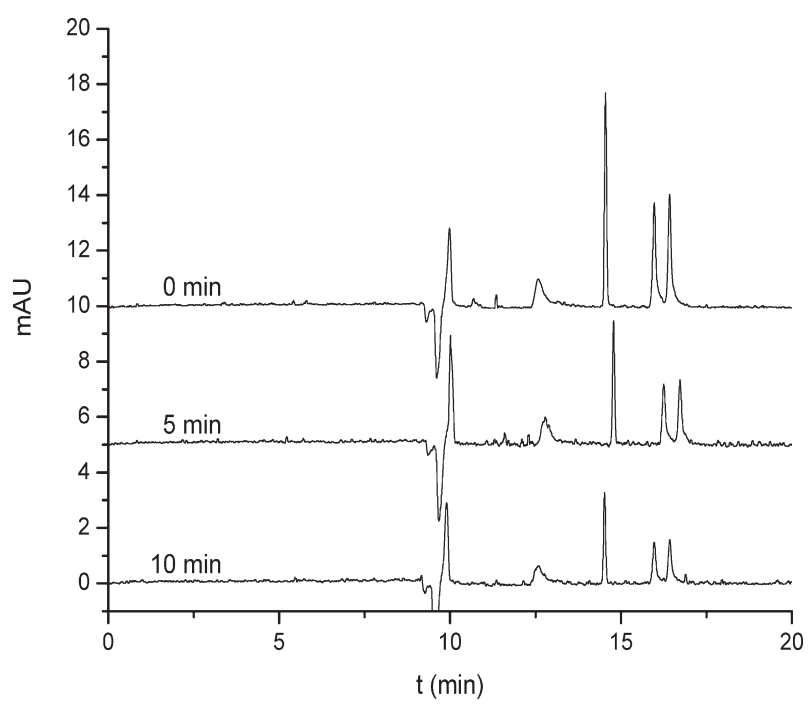

Figure 4. Electropherograms corresponding to the commercial cosmetic product $A$ (diluted in methanol:water $(1: 1 \mathrm{v} / \mathrm{v}))$ applied to an area of skin of $120 \mathrm{~cm}^{2}$ for different times. Separation buffer as in Fig. 3. Other experimental conditions as in Fig. 2.

Table 3. Averaged amount of MBC enantiomers and total MBC measured in the two different commercial cosmetic creams analyzed ${ }^{\text {a) }}$

\begin{tabular}{lllll}
\hline Cosmetic cream & $\begin{array}{l}\text { Amount of first } \\
\text { enantiomer } \\
(\mathrm{mg}) \pm t s / n^{1 / 2}\end{array}$ & $\begin{array}{l}\text { Amount of second } \\
\text { enantiomer } \\
(\mathrm{mg}) \pm t s / n^{1 / 2}\end{array}$ & $\begin{array}{l}\text { Total amount } \\
\text { determined } \\
(\mathrm{mg}) \pm t s / n^{1 / 2}\end{array}$ & $\begin{array}{l}\text { Total label- } \\
\text { ed weight, } \\
\mathrm{mg}\end{array}$ \\
\hline $\mathrm{A}$ & $6.6 \pm 0.3$ & $6.5 \pm 0.3$ & $13.1 \pm 0.6$ & 15 \\
$\mathrm{~B}$ & $4.1 \pm 0.3$ & $4.3 \pm 0.2$ & $8.4 \pm 0.5$ & - \\
\hline
\end{tabular}

a) $s$ is the SD, $t=3.18$ (for a confidence linear range of $95 \%$ ), and $n=3$. 


\section{Concluding remarks}

This work shows that the enantiomeric separation of the sunscreen agent $\mathrm{MBC}$ is possible by EKC using a dual $\mathrm{CD}$ system constituted by the anionic CM- $\beta$-CD (15 mM) and the neutral $\alpha-C D(120 \mathrm{~mm})$ in $100 \mathrm{~mm}$ borate buffer at $\mathrm{pH}$ 9.0. Although the selection of the chiral selector was the most difficult step, the chiral selector concentration and the temperature are two very important factors to be taken into consideration during the development of the chiral method. In addition, the use of a methanol:water $(1: 1 \mathrm{v} / \mathrm{v})$ mixture to dilute standards and samples (previously dissolved in DMF) was necessary in order to avoid peak tailing.

The analytical characteristics of the chiral EKC method developed for the separation of MBC enantiomers were studied and the method was applied to the quantitation of MBC enantiomers in cosmetic creams. After the optimization of the capillary preconditioning, good performance of the method with regards to linearity, precision (instrumental repeatability, method repeatability, intermediate precision), accuracy, and selectivity was achieved. LODs and LOQs determined for MBC enantiomers enabled the quantitation of this compound in commercial cosmetic creams. In addition, this method was also useful to study the skin absorption of MBC from one cosmetic cream (A) with time.

Authors thank the Ministry of Science and Technology (Spain) for the research project BQU2003-03638. C.G.-R. thanks the Ministry of Science and Technology for the Ramón y Cajal program (RYC-2003-001). B.G. thanks CSIC and the RYC-2003-001 project for the grants. Authors also thank Cyclolab (Budapest, Hungary) for the kind gift of $C E-\beta-C D$ used in this work.

Received January 31, 2005

Revised April 22, 2005

Accepted April 26, 2005

\section{References}

[1] Sunscreen chemicals cause health problems (http:// www.coastalguide.org/news/2001-09.html) checked on January 2005.

[2] Marguery, M. C., Rakotondrazafy, J., Sayed, F. E., BayleLebey, P., Journe, F., Bazex, J., Photodermatol. Photo 1995, 11, 209-212.
[3] Orden de 26 de abril de 1999 por la que se adaptan por segunda vez al progreso técnico los anexos de Real Decreto 1599/1997, de 17 de octubre, sobre productos cosméticos. BOE de 6 de mayo de 1999.

[4] Klampfl, C. W., Leitner, T., Hilder, E. F., Electrophoresis 2002, 23, 2424-2429.

[5] Klampfl, C. W., Leitner, T., J. Sep. Sci. 2003, 26, 1259-1262.

[6] Wang, S.-P., Chen, W.-J., Anal. Chim. Acta 2000, 416, 157167.

[7] Wang, S.-P., Lee, W.-T., J. Chromatogr. A 2003, 987, 269275.

[8] Masse, M. O., Herpolborremans, M., Int. J. Cosmetic Sci. 1991, 13, 303-315.

[9] Rastogi, S. C., Jensen, G. H., J. Chromatogr. A 1998, 828, 311-316.

[10] Chisvert, A., Pascual-Martí, M. C., Salvador, A., Fresenius' J. Anal. Chem. 2001, 369, 638-641.

[11] Chisvert, A., Pascual-Martí, M. C., Salvador, A., J. Chromatogr. A 2001, 921, 207-215.

[12] Chisvert, A., Salvador, A., J. Chromatogr. A 2002, 977, 277280.

[13] Smyrniotakis, C. G., Archontaki, H. A., J. Chromatogr. A 2004, 1031, 319-324.

[14] Schakel, D. J., Kalsbeek, D., Boer, K., J. Chromatogr. A 2004, 1049, 127-130.

[15] Chisvert, A., Salvador, A., Pascual-Martí, M. C., Anal. Chim. Acta 2001, 428, 183-190.

[16] Chisvert, A., Vidal, M. T., Salvador, A., Anal. Chim. Acta 2002, 464, 295-301.

[17] García-Ruiz, C., Siderius, M., Ariese, F., Gooijer, C., Anal. Chem. 2004, 76, 399-403.

[18] Fanali, S. (Ed.), Electrophoresis 1999, 20, 2577-2800.

[19] Fanali, S., Chankvetadze, B. (Eds.), Electrophoresis 2001, 22, 3077-3354.

[20] Nishi, H., Terabe, S. (Eds.), J. Chromatogr. A 2000, 875, 1471.

[21] Wren, S. A. C. (Ed.), Chromatographia 2001, 54, S5-S93.

[22] Chankvetadze, B., Fanali, S. (Eds.), Electrophoresis 2003, 24, 2407-2732.

[23] Chankvetadze, B. (Ed.), Capillary Electrophoresis in Chiral Analysis, John Wiley \& Sons, Chichester, UK 1997.

[24] Schaeper, J. P., Sepaniak, M. J., Electrophoresis 2000, 21, 1421-1429.

[25] Miller, J. N., Miller, J. C., Statistics and Chemometrics for Analytical Chemistry, 3rd edn., Harlow, England 2000, pp. 122-123.

[26] García-Ruiz, C., Marina, M. L., Electrophoresis 2000, 21 , 1565-1573.

[27] García-Ruiz, C., Marina, M. L., Electrophoresis 2001, 22, 3191-3197.

[28] García-Ruiz, C., Martín-Biosca, Y., Crego, A. L., Marina, M. L., J. Chromatogr. A 2001, 910, 157-164. 